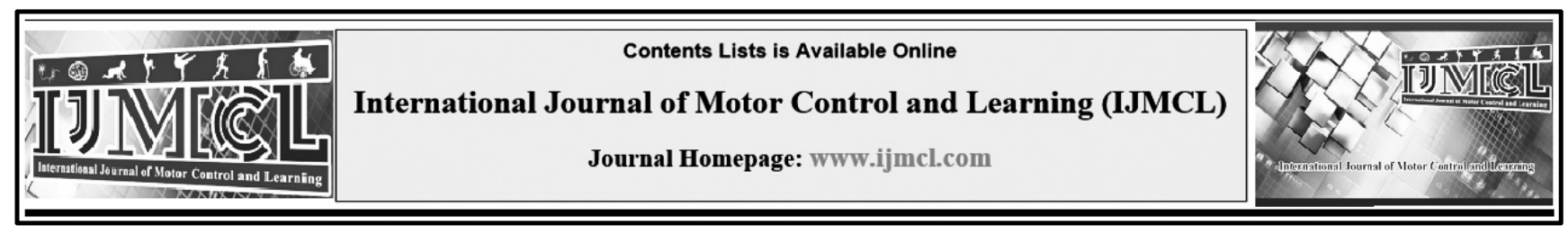

\title{
Development and Validation of the Kabaddi Offensive and Defensive Observational Instrument
}

\author{
Mohammad Maleki ${ }^{a^{*}}$, Shadi Abdollahi ${ }^{\mathrm{b}}$ \\ ${ }^{a}$ Department of Physical Education, Faculty of Humanities and Social Sciences, University of Kurdistan, Sanandaj, Kurdistan, Iran
}

${ }^{\mathrm{b}}$ University of Allameh Tabataba'i, Tehran, Iran

\begin{tabular}{l}
\hline Keywords \\
\hline Behavior \\
Defensive \\
Kabaddi \\
Observational Instrument \\
Offensive
\end{tabular}

\begin{abstract}
Background: Identify techniques and tactics and their analysis in training sessions, in addition to providing accurate information to improve the weaknesses of the team, help the coach in the training process and identify physical, behavioural, and technical requirements of players.

Objective: This study, through the principles of observational approach, aims to development and validation of an instrument to analyse observable behaviours during a kabaddi match.

Method: For this purpose, four matches of Iranian men's kabaddi team and five Iranian women's kabaddi team in the Incheon Asian Games in South Korea in 2014 were selected for this study. At first for higher transparency of the aspects of kabaddi play, describing offensive and defensive behaviours were revise and clarified; The final version was provided to 10 experienced coaches and teachers of kabaddi to determine the content validity and Intra-rater and inter-rater methods used for determining the reliability by two people, including a coach and a referee. To coordinate between the observers in the process of assessing reliability of kabaddi defensive and offensive behaviours, the beginning and end of each raid were coded into a behaviour unit. In each behaviour unit, the raiding player's offensive behaviour and the opponent's defensive behaviour were simultaneously coded.

Results: In this instrument, results of means of content validity index for offensive and defensive behaviours at 0.05 significance level were 0.8 and 0.89 , respectively. The results for means of intra-observer reliability for both categories of offensive and defensive behaviours $\mathrm{k}=0.99$ and $\mathrm{k}=0.97$ were obtained, respectively. The mean of inter-observer reliability for categories of offensive and defensive behaviours were $\mathrm{k}=0.89$ and $\mathrm{k}=0.88$, respectively, indicating high agreement between the two raters.

Conclusion: Observational design of the current research had a high power to collect, manage, and analyse data by a precise definition of the skills and kabaddi variables. Then, this instrument can be used as a suitable observational instrument by coaches to identify and analyse kabaddi's defensive and offensive performances.
\end{abstract}

Mohammad Maleki,

Email: mo.maleki@uok.ac.ir

Received: 2021/03/13

Accepted: 2021/05/19

Published: 2021/05/29

\section{Introduction}

Success in open and interactive sports requires the use of specialized instruments to identify techniques and tactics and their analysis in training sessions. In addition to providing accurate information to improve the weaknesses of the team, such analyses help the coach in the training process and identify physical, behavioural, and technical requirements of players (Gómez, Lorenzo, Ibañez,
\& Sampaio, 2013; MD Hughes, Hughes, \& Behan, 2009; Ortega, Palao, Gómez, Lorenzo, \& Cárdenas, 2007; Sainz De Baranda, Ortega, \& Palao, 2008). The scientific field of performance analysis seeks to classify and quantify important aspects of athletic performance. It has the ability to provide appropriate feedback to coaches and athletes to improve their future performances (Mike Hughes \& Franks, 2004; M. D. Hughes \& 
Bartlett, 2002). The Notational System is a valid method for recording athletic performance in which the player's actions during the competition will be considered (Mike Hughes \& Franks, 2004). Researches have paid the most attention to notational performance analysis in team sports like football (Bloomfield, Polman, \& O'donoghue, 2005; Clark, 2010), rugby (Dave, Craig, Shayne, Ceri, \& Kevin, 2009), and volleyball (Drikos \& Vagenas, 2011). One of the team sports that has received very little attention is kabaddi. Due to technical and tactical dynamics as well as its interactive competitive environment, this sport can benefit a lot from performance analysis.

Kabaddi is a sport in which the raider must move into the defence area of the opponents and continuously express the term «kabaddi» while trying to touch the opponent players, and then return into his own area. Defenders should try to catch the raider, so that he does not get back to his area. If the raider is able to touch the defenders and successfully return to his area, points will be awarded to the raiding team. The defending team will not get a point, unless they catch the raiding player. This sport is played in many Asian countries and in 1990 was officially entered into the Asian Games in Beijing (11).

Observational methodology is an appropriate way to study exercise and help trainers to design and develop quantitative and qualitative practice and match sessions (Anguera \& Mendo, 2013). The condition for usefulness of this approach is accurate data collection, which itself requires an instrument with acceptable validity and reliability (Creswell, 2005). In terms of application, this approach has the ability to directly collect data in training and match. In terms of content, they can also be used for the development of knowledge and objective evaluation of training effectiveness. Therefore, observational instruments have a lot of content and training importance in the field of sports. The great diversity of situations that can be recorded by careful observation shows that complete reliance on common instruments and standards is not ideal. But, it is essential to design ad hoc instruments in any area (Anguera \& Mendo, 2013). The validity subject of the evaluation instrument was emphasized in sport performance analysis. This is one of the prospects of appropriate statistical methods to establish the inter-rater agreement. To understand which observational instrument of sports performance analysis is the best and most reliable standardization discussions are deemed necessary (14).

In research literature, few studies have dealt with the design and development of observational instruments of kabaddi. As far as we know, Palraj (2012) (Palraj, Needhiraja, John, \& Kalidasan, 2012), in the first study tried to design and develop a digital system for the analysis of kabaddi tournaments. They used South Zone InterUniversity Kabaddi tournament in India in 20102011 to make reliability. After consultation with 15 players, coaches, and physical education teachers, 16 scoring indicators were identified such as the total number of points in each team, the total number of successful and unsuccessful raids of each team, the total number of successful and unsuccessful defence of each team, the number of 
lonas $^{1}$ set and time-outs of each team as key performance indicators. After designing the software, the mentioned final tournament was analysed. The researchers found that the analysis instrument of kabaddi performance indicators have a good efficiency in training sessions and physical education classes. They used scoring indicators only as performance indicators (M. D. Hughes \& Bartlett, 2002) that hid other offensive and defensive behaviours of players from the coach's eyes. But this research is a study that directly designs Kabaddi Offensive and Defensive Observational Instrument (KODOI) which can be addressed in both training and match sessions.

Because of the different variables in any sporting competition, the interaction between them and the difficulty of controlling context variables, there is a need to use observational methodology to analyse the behaviour (Anguera \& Mendo, 2013). For this purpose, this study follows the principles of observational approach to use special scientific strategy that aims to analyse observable behaviours during a kabaddi match. In this way, important motor behaviours of kabaddi can be collected, recorded, and validated. Then, the aim of this study is whether KODOI, based on observational approach, will be a suitable instrument to analyse offensive and defensive performances in Kabaddi?

\section{Method}

Because Iran won silver medal in both men and women matches, in order to access more observable and high-level performances in

\footnotetext{
${ }^{1}$. In Kabaddi when all the players get out of the opposite team, this is termed as lona.
}

Kabaddi, four matches of Iran's men's kabaddi team versus India, Pakistan, Japan, and South Korea, and five Iranian women's kabaddi team versus Thailand, Taiwan, Japan, Bangladesh, and India (nine matches totally) in the Incheon Asian Games in South Korea in 2014 were selected for this study. Asian Games brings together the best kabaddi teams, players, and coaches. The results of this tournament are also very reliable (11). These competitions are held once every four years.

In accordance with Specific Taxonomy methods of observational studies in sports science, the observational instrument of this study was the category systems-field format (Anguera \& Mendo, 2013). Features of this instrument of kabaddi performance analysis include plurality (four teams of men and women in the kabaddi semi-finals of the Incheon Asian Games in South Korea, 2014), follow-up (recording the players' behaviour during several matches) and multi-dimensional. Behaviours under investigation of every observational instrument should have two features of exhaustiveness and mutual exhaustiveness in terms of content. Exhaustiveness means that the investigated behaviour belongs to one of the behavioural categories and mutual exhaustiveness means that there should be no interference between behavioural categories (Anguera \& Mendo, 2013). The performance of athletes in kabaddi matches is measured by techniques leading to earning points, which means touching some parts of the opponent's body and escaping from the opponents' area (offensive phase) or performing techniques that 
prevent the return of the raider to their own area (defensive phase). First, a list of motor behaviours of kabaddi was extracted by researchers (Anguera \& Mendo, 2013), which contains offensive behaviours of touching by hand (4 behaviours), touching with toes (5 behaviours), touching by leg ( 1 behaviours), kicking ( 3 behaviours) and bonus ( 2 behaviours), and defensive behaviours include holding ankles (3 behaviours), the thigh (3 behaviours), the knees ( 1 behaviours), holding the waist and bust ( 2 behaviours), blocking (3 behaviours) and chaining (3 behaviours) (Rao, 1983). These actions which make up kabaddi's performance indicators were classified into 15 offensive behaviours and 17 defence behaviours. These indicators were described by 13 experienced club coaches $\left(\mathrm{M}_{\mathrm{age}}=43, \mathrm{SD}=1.8\right)$ of the Kabaddi Federation of the Islamic Republic of Iran. Then their exhaustiveness and mutual exhaustiveness were investigated by 3 coaches $\left(\mathrm{M}_{\mathrm{age}}=40, \mathrm{SD}=2.3\right)$ and 3 Kabaddi players $\left(\mathrm{M}_{\mathrm{age}}=26, \mathrm{SD}=1.1\right)$ with 7 to 10 years of national and international experience during three sessions of observing videos of professional kabaddi games (Anguera \& Mendo, 2013).
Experts in each field have an important role in improving the quality of observational measurement instrument (Ortega et al., 2007). Experts' duty in qualitative assessment of measurement instrument of the current study included revision and clarification of describing offensive and defensive behaviours for higher transparency of the aspects of kabaddi play. Among 32 primary items that were proposed for the kabaddi defensive and offensive behaviours, 6 items including touching by hand (jumping), touching by toes (Retreat and implementation of the touch by toes skills, and touching by toes with natural running (walking fast)), touching by leg, kicking (kicking to the sides, and kicking roll), and 3 defensive items, including holding thigh (taking one step and holding thigh), holding knee (holding ankle and then turn into a bend of the knee) and holding wrist (holding wrist from the bottom) were modified through changing some words and definition to clarify the items, according to experts' advice. Finally, after revisions, 32 descriptions were included in two categories of offensive and defensive behaviours (Table 1).

Table 1. Describing the kabaddi offensive behaviours, percentage, and content validity index resulting from the judgment of experts in the three-point rating scale.

\begin{tabular}{lllll}
\hline $\begin{array}{l}\text { Techniques } \\
\text { (skills) }\end{array}$ & type & Definition & CVR & CVI \\
\hline & Running & The hand hit associated with running or walking fast & 1 \\
\cline { 2 - 5 } Touch by \\
hand
\end{tabular}




\begin{tabular}{|c|c|c|c|c|}
\hline & implementation of the & touch by toes & & \\
\hline & $\begin{array}{l}\text { With natural running } \\
\text { (walking fast) }\end{array}$ & $\begin{array}{l}\text { Touching by toes with a sudden turn when the attacker } \\
\text { running from one half to the other half }\end{array}$ & -0.6 & 1 \\
\hline & During walking & $\begin{array}{l}\text { The action of reversing the attacker's foot print to correct the } \\
\text { direction of attack }\end{array}$ & 0.6 & 1 \\
\hline $\begin{array}{l}\text { Touch by } \\
\text { leg }^{3}\end{array}$ & & $\begin{array}{l}\text { Drag and reaching out of the Raider attack leg from each side } \\
\text { to touch the defense }\end{array}$ & -0.6 & 1 \\
\hline \multirow{3}{*}{ Kick $^{4}$} & Kicking back & When defender to attacker comes back & 1 & 1 \\
\hline & Kicking to the sides & When defender to attacker comes back & 0.2 & 0.6 \\
\hline & Kicking roll & $\begin{array}{l}\text { Cover more space and redirect execution by an attacker (the } \\
\text { raider attack's toe rolled the sides from behind) }\end{array}$ & -0.2 & 1 \\
\hline \multirow{2}{*}{$\begin{array}{l}\text { Bonus } \\
\text { Point }\end{array}$} & $\begin{array}{l}\text { With guide foot of } \\
\text { attacker }\end{array}$ & \multirow{2}{*}{$\begin{array}{l}\text { Attacker cross the bonus line before the conflict and contacts } \\
\text { with the defenders so that no part of his body before the bonus } \\
\text { line is not in contact and whenever is running out for at least } \\
\text { six defenders on the pitch and when a person is disqualification } \\
\text { with the five people will be applicable }\end{array}$} & 1 & 1 \\
\hline & $\begin{array}{l}\text { With back foot of } \\
\text { attacker }\end{array}$ & & 1 & 1 \\
\hline
\end{tabular}

\begin{tabular}{|c|c|c|c|c|}
\hline $\begin{array}{l}\text { Techniques } \\
\text { (skills) }\end{array}$ & type & Definition & CVR & CVI \\
\hline \multirow{3}{*}{ Holding Ankle } & $\begin{array}{l}\text { During getting } \\
\text { bonus point by } \\
\text { attacker }\end{array}$ & \multirow{3}{*}{$\begin{array}{l}\text { Holding grip } \\
\text { attacker's ankle with } \\
\text { the both hands and } \\
\text { lifting and pulling } \\
\text { the Attacker's feet } \\
\text { off the ground and } \\
\text { rotate the defence to } \\
\text { the ends of the field }\end{array}$} & 1 & 1 \\
\hline & $\begin{array}{l}\text { Holding } \\
\text { attacker's guide foot } \\
\text { ankle }\end{array}$ & & 1 & 1 \\
\hline & $\begin{array}{l}\quad \text { Holding } \\
\text { attacker's back } \\
\text { ankle by corner } \\
\text { Players by using leg } \\
\text { switch }\end{array}$ & & 1 & 1 \\
\hline \multirow{3}{*}{ Holding Thigh 5} & $\begin{array}{l}\text { With the jump } \\
\text { forward }\end{array}$ & $\begin{array}{l}\text { Jumping move } \\
\text { forward by defence } \\
\text { for better advocate } \\
\text { to access the } \\
\text { attacker and execute } \\
\text { the skill of thigh }\end{array}$ & 0.6 & 0.8 \\
\hline & $\begin{array}{l}\text { Taking one step } \\
\text { and holding thigh }\end{array}$ & \begin{tabular}{l}
\multicolumn{1}{c}{ the skill of } \\
holding attacker's \\
thigh on defence's \\
back foot
\end{tabular} & 0.2 & 1 \\
\hline & From behind & $\begin{array}{l}\text { the skill of } \\
\text { holding attacker's } \\
\text { thigh especially for } \\
\text { the corner point of } \\
\text { kabaddi field }\end{array}$ & -0.2 & 0.6 \\
\hline Holding Knee & $\begin{array}{l}\text { Holding ankle } \\
\text { and then turn into a } \\
\text { bend of the knee }\end{array}$ & $\begin{array}{l}\text { Like holding } \\
\text { thigh skill but the } \\
\text { difference is that the } \\
\text { defence take } \\
\text { Attacker's knee joint }\end{array}$ & -0.2 & 1 \\
\hline \multirow{2}{*}{$\begin{array}{l}\text { Holding Waist } \\
\text { and Bust }\end{array}$} & $\begin{array}{c}\text { Holding waist } \\
\text { chest to chest or face }\end{array}$ & \multirow{2}{*}{$\begin{array}{l}\text { The skill if } \\
\text { holding waist or bust } \\
\text { by the defenders } \\
\text { behind the attacker }\end{array}$} & 1 & 1 \\
\hline & $\begin{array}{l}\text { Holding waist } \\
\text { from behind of } \\
\text { attacker }\end{array}$ & & 1 & 1 \\
\hline \multirow[t]{2}{*}{ Holding Wrist } & From above & \multirow{2}{*}{$\begin{array}{l}\quad \text { Firmer grip } \\
\text { attacker's wrist by } \\
\text { defenders }\end{array}$} & -1 & 0.8 \\
\hline & $\begin{array}{l}\text { From down of } \\
\text { attacker's body }\end{array}$ & & -0.6 & 1 \\
\hline Blocking $^{6}$ & Block sudden & $\begin{array}{c}\text { Wide-standing } \\
52\end{array}$ & 1 & 1 \\
\hline
\end{tabular}




\begin{tabular}{|c|c|c|c|c|}
\hline & $\begin{array}{l}\text { aggressive and with } \\
\text { a little jump }\end{array}$ & $\begin{array}{l}\text { defender and curved } \\
\text { body with a small } \\
\text { jump forward to the } \\
\text { attacker path for } \\
\text { approaching him } \\
\text { while body weight is } \\
\text { on guide foot }\end{array}$ & & \\
\hline & $\begin{array}{l}\text { Blocking while } \\
\text { attacker moving } \\
\text { forward }\end{array}$ & $\begin{array}{l}\text { Fast forward in } \\
\text { order to cover the } \\
\text { distance and caught } \\
\text { the striker in an } \\
\text { unexpected position }\end{array}$ & 1 & 1 \\
\hline & $\begin{array}{l}\text { Blocking with } \\
\text { march }\end{array}$ & $\begin{array}{l}\text { Defender moves } \\
\text { back in order to } \\
\text { block attacker path }\end{array}$ & 1 & 1 \\
\hline \multirow[b]{3}{*}{ Chaining } & $\begin{array}{l}\text { Chaining with } \\
\text { the central player or } \\
\text { Corner }\end{array}$ & $\begin{array}{l}\text { A state in which } \\
\text { centre or corner } \\
\text { players apply the } \\
\text { chaining }\end{array}$ & 1 & 1 \\
\hline & $\begin{array}{l}\text { Keep successive } \\
\text { chain }\end{array}$ & $\begin{array}{l}\text { The way chain } \\
\text { ring round attacker } \\
\text { when the chain must } \\
\text { also be compact }\end{array}$ & 0.6 & 1 \\
\hline & $\begin{array}{l}\quad \text { Keep an ongoing } \\
\text { chain or } \\
\text { Substitution }\end{array}$ & $\begin{array}{l}\text { This chaining is } \\
\text { not against attacker } \\
\text { but behind him is } \\
\text { formed and centre } \\
\text { defender players } \\
\text { pursue behind the } \\
\text { attacker to chase } \\
\text { him out from the } \\
\text { lobby areas }\end{array}$ & 1 & 1 \\
\hline
\end{tabular}

Note: 1: Forward reach out to the nearest defender to hit and for the creation of the position of fighting; 2: Drag and reaching out to touch and hit the attacker on each side of the defense; 3: Drag and reaching out of the Raider attack leg from each side to touch the defense 4: Aggressive attack with wide open leg to touch defender; 5: The act of taking the attacker's hip by two-handed from defence to prevent the escape attacker when attacker does not have great speed; 6: When the defence comes in the form of a barrier wall, they hold attacker and are trying to prevent his escape in two forms: stand up parallel and diagonal.

\section{Validity}

The final version was provided to 10 experienced coaches of kabaddi (3 women) to determine the content validity. They stated their opinion about the description quality of each item in the three-point rating scale with 'appropriate', 'somewhat appropriate', and 'inappropriate' (Table 1).

\section{Reliability}

Due to the large variability in different moments of any sporting contest, the best way to assess reliability in the field of sports performance analysis is intra- and inter-observer reliability (O'Donoghue \& Ingram, 2001). Intra-rater and inter-rater methods used for determining the reliability by two people, including a coach and a referee, with 8 and 5 years of experience respectively, and no history of notational sports performance analysis. They underwent eight hours of training for notational performance analysis on Korea vs. India (men matches) and Thailand vs. India (women matches). These two matches were not included in final analysis. The training was 
regarding coordination on how to accurately recognize and record performances, identify them as offensive or defensive behaviours as well as making decisions about them. Then, for the intrarater method, a kabaddi coach notated one of the games with a two-week interval to reduce the impact of learning and familiarity. In the inter-rater method, one men's match and one women's match were evaluated by the two evaluators. To coordinate between the observers in the process of assessing reliability of kabaddi defensive and offensive behaviours, the beginning and end of each raid were counted as a behaviour unit. For example, once the raider performed an offensive behaviour until completion of the opponent's one was identified as a behaviour unit. In each behaviour unit, the raiding player's offensive behaviour and the opponent's defensive behaviour were simultaneously coded. Table 2 shows the number of behaviour units observed in each match.

Table 2. Number of behaviour units of Iran's Kabaddi team's matches versus opponents at the Incheon Asian Games 2014.

\begin{tabular}{|c|c|c|c|c|c|c|}
\hline & Matches & $\begin{array}{l}\text { No. } \\
\text { offenses } \\
\text { (Iran) }\end{array}$ & $\begin{array}{l}\text { No. } \\
\text { defences } \\
\text { (Iran) }\end{array}$ & $\begin{array}{l}\text { No. offenses } \\
\text { (Opponent) }\end{array}$ & $\begin{array}{l}\text { No. defences } \\
\text { (Opponent) }\end{array}$ & $\begin{array}{l}\text { Behaviour } \\
\text { Units Totally }\end{array}$ \\
\hline \multirow{4}{*}{ Male } & Iran-India & 41 & 39 & 39 & 41 & 160 \\
\hline & Iran-Pakistan & 45 & 44 & 44 & 45 & 178 \\
\hline & $\begin{array}{l}\text { Iran-South } \\
\text { Korea }\end{array}$ & 27 & 27 & 27 & 27 & 108 \\
\hline & Iran-Japan & 46 & 47 & 47 & 46 & 186 \\
\hline \multirow{6}{*}{ Female } & Iran-India & 34 & 34 & 34 & 34 & 136 \\
\hline & $\begin{array}{l}\text { Iran- } \\
\text { Bangladesh }\end{array}$ & 32 & 32 & 32 & 32 & 128 \\
\hline & Iran-Japan & 35 & 35 & 35 & 35 & 140 \\
\hline & Iran-Taiwan & 39 & 39 & 39 & 39 & 156 \\
\hline & Iran-Thailand & 33 & 33 & 33 & 33 & 132 \\
\hline & Total & 332 & 330 & 330 & 332 & 1324 \\
\hline
\end{tabular}

\section{Results}

\section{Validity}

Results of means of content validity index for offensive and defensive behaviours were 0.8 and 0.89 , respectively (From 0.68 to 1 for both indicators, Table 1). These results confirmed the validity of the instrument after corresponding with CVR calculation table at 0.05 significance level.

\section{Reliability}

The kabaddi offensive and defensive behaviours were rated by a group of experts. Thus to assess the reliability of the intra- and inter-rater, Cohen's kappa method was used to evaluate the kabaddi offensive and defensive behaviours (Robinson \& O'Donoghue, 2007). The results for means of intra-observer reliability for both categories of offensive and defensive behaviours $\mathrm{k}$ $=0.99$ and $\mathrm{k}=0.97$ were obtained, respectively. The mean of inter-observer reliability for categories of offensive and defensive behaviours were $\mathrm{k}=0.89$ and $\mathrm{k}=0.88$, respectively, indicating high agreement between the two raters (Table 3). 
Table 3. Results of kappa correlation coefficients of the judgment of the two rater from the number of observed offensive and defensive performance indicators of men's and women's kabaddi matches.

\begin{tabular}{|c|c|c|c|c|c|c|c|}
\hline \multirow{2}{*}{\multicolumn{2}{|c|}{ Behaviours }} & \multicolumn{3}{|c|}{ Matches for male } & \multicolumn{3}{|c|}{ Matches for female } \\
\hline & & $\begin{array}{l}\text { First } \\
\text { rater }\end{array}$ & $\begin{array}{l}\text { Second } \\
\text { rater }\end{array}$ & kappa & $\begin{array}{l}\text { First } \\
\text { rater }\end{array}$ & $\begin{array}{l}\text { Second } \\
\text { rater }\end{array}$ & kappa \\
\hline \multirow{5}{*}{ Offense } & Touch by hand & 441 & 442 & 0.91 & 571 & 573 & 0.89 \\
\hline & Touch by toes & 396 & 394 & 0.89 & 260 & 261 & 0.9 \\
\hline & Touch by leg & 238 & 239 & 0.91 & 131 & 128 & 0.87 \\
\hline & Kicking & 80 & 81 & 0.91 & 79 & 80 & 0.9 \\
\hline & Bonus point & 94 & 92 & 0.89 & 134 & 129 & 0.84 \\
\hline \multirow{7}{*}{ Defense } & Blocking & 60 & 58 & 0.89 & 81 & 83 & 0.89 \\
\hline & Chaining & 72 & 71 & 0.91 & 71 & 70 & 0.9 \\
\hline & Holding ankle & 34 & 36 & 0.89 & 48 & 45 & 0.86 \\
\hline & Holding thigh & 21 & 23 & 0.89 & 14 & 17 & 0.86 \\
\hline & Holding knee & 1 & $\mathbf{0}$ & 0.91 & 5 & 7 & 0.87 \\
\hline & $\begin{array}{l}\text { Holding waist and } \\
\text { bust }\end{array}$ & 29 & 31 & 0.89 & 49 & 51 & 0.89 \\
\hline & Holding wrist & $\mathbf{0}$ & 1 & 0.91 & 5 & 3 & 0.87 \\
\hline
\end{tabular}

\section{Discussion and Conclusion}

This research aims to design, validate, and assess the reliability of KODOI by which the skill behaviours of kabaddi can be assessed. Content validity of KODOI was confirmed by experienced and professional coaches in terms of suitability of offensive and defensive behaviours description of kabaddi. First, the description of kabaddi offensive and defensive behaviours was provided (32 items). Then the panels of specialists approved the final version (32 items) by modifying the description of some behaviour. Results of validity and reliability of the KODOI showed that it would be a good and reliable instrument for Kabaddi's coaches to analyse the players' offensive and defensive performances.

This observational behaviour was among the event-based sampling (Anguera \& Mendo, 2013) for researchers to study the number, intensity, and duration of behaviour emergence. The strongest point of this study is training observers to increase judgment coordination. In the field of sports, because the situation varies from one observation to the other, thus one cannot use the test-retest method to investigate the reliability of the observational instrument (O'Donoghue \& Ingram, 2001). Therefore, the best method of reliability assessment in observational methods is using intraand inter-observer reliability. In order to examine the properness of the confirmed behaviours with their occurrence in real game situations, the evaluators were asked to notate professional tournaments of kabaddi by KODOI, because gaining relevant and clear information about sportspecific offensive and defensive behaviours is very important in sports performance assessment instruments (Oslin, Mitchell, \& Griffin, 1998).The results of the inter- and intra-rater observer shows the high accuracy of the KODOI items in the notation of the number and target of kabaddi offensive and defensive behaviours in terms of game real world.

Although in the research literature in the field of team sports notational performance analysis, there was no study in kabaddi for comparison, however, the results have shown that the reliability 
level of inter-observer is usually lower than intraobserver reliability (Tucker, Mellalieu, James, \& Taylor, 2005). These differences appear when the assessment instrument includes a large number of operational definitions of skills (Tucker et al., 2005). On the other hand, O'Donoghue (2007)(O'Donoghue \& Ingram, 2001) argues that the precise operational definitions alone cannot guarantee reliability, but the acceptable knowledge of evaluators from the behaviours under analysis is more important. Results of this study also confirmed it. The reason for this issue can be the difference in the level of understanding of the observers from the video performance analysis and their different understandings of the operational definition of kabaddi indicators. Also, the interactive and dynamic nature of kabaddi competitions leads to the inevitability of the interand intra-observer errors (M Hughes, Cooper, \& Nevill, 2002),therefore maybe 8 hours of training for evaluators' coordination is insufficient.

The difference between Kabaddi and other group invasion games is that always in the kabaddi, the offensive behaviour is carried out by one raider, but the defensive behaviour is done by several players of an opponent team. In other words, in many kabaddi tournaments, several defenders are defending at the same time. This may lead to complexity in analysing and a different understanding of the evaluators regarding defensive behaviour. In the results of the present investigation, it was found that the inter-observer reliability in the defensive behaviours is lower than the offensive behaviour ( $\mathrm{k}=0.88$ vs. $\mathrm{k}=0.89$ ). As mentioned earlier, kabbadi consists of a lot of interaction between the player and the opponents. In each behaviour unit, the raid and defence action must be examined in interaction with each other. This is because performance of the match it is the result of a confrontation between two different teams, therefore the different aspects of the performance are appeared (Gréhaigne, 1991).Motor behaviours are affected by many factors in sports competitions (Lebed, 2006). This has made it difficult to design instruments that cover all aspects of data collection. Since the limitations of KODOI were ignoring the interaction between the raider and the defender of Kabaddi, thus it is suggested that future studies, in addition to recording raiding and defensive behaviours, analyse their interaction as well.

Match location has a significant effect on the performance of players (Bray \& Martin, 2003). In research literature, several studies have shown the technical and tactical behaviour differences as a function of the match location (Lago \& Martín, 2007). Validity and reliability of KODOI was measured by the videotaped Kabaddi matches at the Asian game's tournament in Incheon South Korea in 2014. The host country was just a match against Iran. Thus, the effect of the match location could not be investigated for the analysed matches. Therefore, it is suggested to investigate the reliability of these instruments in the form of longitudinal research design, during the kabaddi league that includes guest-host effect as well.

This study showed that specific and detailed definition of the components and sub-behaviours of offense and defence and ways of recording Kabaddi events can help evaluators understand 
better what behaviours need to be focused on during training and match, as well as which offensive and defensive behaviours have the most frequency. KODOI provides useful information about the organization, game style and the strengths and weaknesses of one's and opponents' team to coaches and team managers (Ortega et al., 2007). This instrument can be used in the process of self-assessment that is implemented by athletes and coaches during training sessions to assess the learning stages of kabaddi motor skills. KODOI is appropriate for the use and implementation of observational designs and analysis of acquisition process for kabaddi offensive and defensive behaviours in assessments during and after training (videotaped training sessions). Observational design of the current research had a high power to collect, manage, and analyse data by a precise definition of the skills and kabaddi variables. It is suggested that future studies measure psychometric properties of this instrument by cross-sectional research design on young and adolescent kabaddi players.

\section{References}

1. Anguera, M. T., \& Mendo, A. H. (2013). OBSERVATIONAL METHODOLOGY IN SPORT SCIENCES. E-balonmano. com: Journal of Sports Science/Revista de Ciencias del Deporte, 9(3).

2. Bloomfield, J., Polman, R., \& O'donoghue, P. (2005). Effects of score-line on team strategies in FA Premier League Soccer. Journal of Sports Sciences, 23(2), 192-193.

3. Bray, S., \& Martin, K. (2003). The effect of competition location on individual athlete performance and psychological states. Psychology of Sport and Exercise, 4(2), 117-123.

4. Clark, P. (2010). Intermittent high intensity activity in English FA Premier League soccer. International
Journal of Performance Analysis in Sport, 10(2), 139-151.

5. Creswell, J. W. (2005). Research design: qualitative, quantitative, and mixed method approaches (2nd ed.). london: sage.

6. Dave, S., Craig, T., Shayne, H., Ceri, N., \& Kevin, L. (2009). Semi-automated time-motion analysis of senior elite rugby league. International Journal of Performance Analysis in Sport, 9(1), 47-59.

7. Drikos, S., \& Vagenas, G. (2011). Multivariate assessment of selected performance indicators in relation to the type and result of a typical set in Men's Elite Volleyball. International Journal of Performance Analysis in Sport, 11(1), 85-95.

8. Gómez, M.-A., Lorenzo, A., Ibañez, S.-J., \& Sampaio, J. (2013). Ball possession effectiveness in men's and women's elite basketball according to situational variables in different game periods. Journal of Sports Sciences, 31(14), 1578-1587.

9. Gréhaigne, J. (1991). A new method of goal analysis. Science and Football, 5, 10-16.

10. Hughes, M., Cooper, S., \& Nevill, A. (2002). Analysis procedures for non-parametric data from performance analysis. International Journal of Performance Analysis in Sport, 2(1), 6-20.

11. Hughes, M., \& Franks, I. M. (2004). Notational analysis of sport: Systems for better coaching and performance in sport: Psychology Press.

12. Hughes, M., Hughes, M., \& Behan, H. (2009). Computerized notational analysis and performance profiling in racket sports. Lees, Cabello \& Torres (eds). Science and Racket Sports IV, 187-196.

13. Hughes, M. D., \& Bartlett, R. M. (2002). The use of performance indicators in performance analysis. Journal of Sports Sciences, 20(10), 739-754.

14. Lago, C., \& Martín, R. (2007). Determinants of possession of the ball in soccer. Journal of Sports Sciences, 25(9), 969-974.

15. Lebed, F. (2006). System approach to games and competitive playing. European Journal of Sport Science, 6(01), 33-42.

16. O'Donoghue, P., \& Ingram, B. (2001). A notational analysis of elite tennis strategy. Journal of sports sciences, 19(2), 107-115.

17. Ortega, E., Palao, J. M., Gómez, M. á., Lorenzo, A., \& Cárdenas, D. (2007). Analysis of the efficacy of possessions in boys' 16 -and-under basketball teams: differences between winning and losing teams. Perceptual and motor skills, 104(3), 961-964.

18. Oslin, J. L., Mitchell, S. A., \& Griffin, L. L. (1998). The game performance assessment instrument (GPAI): Development and preliminary validation. Journal of teaching in physical education, 17(2), 231-243.

19. Palraj, A., Needhiraja, A., John, L., \& Kalidasan, R. (2012). Design and development of digital match analysis system for kabaddi matches. Educational 
Technology, Elixir Edu. Tech. 50 (2012) 10387, 10389.

20. Rao, C., V. (1983). Kabaddi; Native Indian Sports. Patiala: NIS Publication.

21. Robinson, G., \& O'Donoghue, P. (2007). A weighted kappa statistic for reliability testing in performance analysis of sport. International Journal of Performance Analysis in Sport, 7(1), 1219.

22. Sainz De Baranda, P., Ortega, E., \& Palao, J. M. (2008). Analysis of goalkeepers' defence in the World Cup in Korea and Japan in 2002. European Journal of Sport Science, 8(3), 127-134.

23. Tucker, W., Mellalieu, S. D., James, N., \& Taylor, J. B. (2005). Game location effects in professional soccer: A case study. International Journal of Performance Analysis in Sport, 5(2), 23-35. 